\title{
Member Views of Materials News: 2011 Edition
}

\author{
Lynne Robinson
}

$J O M$ asked an array of TMS members to comment on what they believed was the most significant news of 2011, from a materials perspective. A number of responses drew from general media coverage, while others highlighted developments reported in technical conferences and publications. Many of the individuals who participated in this article are involved with TMS technical or administrative committees, and their comments reflect those particular interests.

What follows are excerpts from the exceptional contributions to this article. The full text of these responses, as well as links to resources referenced in many of them, can be accessed at Materials Technology @ TMS at materialstechnology.tms.org.

\section{J. Ciulik}

\section{Senior Consultant,}

Element Materials Technology

Vice Chair, Refractory Materials

Committee

In my view, the most significant development this year in refractory metals has been the production of tungstenrhenium alloys with hafnium carbide additions. Rhenium Alloys Inc. has developed tungsten- $25 \mathrm{wt} . \%$ rhenium with $2 \mathrm{wt} . \%$ to $4 \mathrm{wt} \% \%$ hafnium carbide particles which act as a dispersion strengthening addition. This "metal-matrix composite" has $50 \%$ to $70 \%$ higher yield strength and $50 \%$ to $90 \%$ higher tensile strength at elevated temperatures than the conventional tungsten-25wt.\% rhenium alloy, making it a very promising material for friction stir welding tools. In 2012 and beyond, HfC-strengthened tungsten-rhenium alloys have the potential to dramatically increase friction stir welding tool life.
Rachel DeLucas

Process Engineer

Member, Young Leader Committee

I believe the most significant devel-

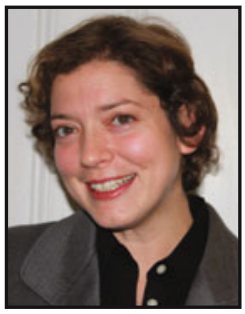
opment this year is the meaningful increase in spending on energy research, both by the government and private industry. These investments will provide resources for new research in materials related to energy storage and production, as well as encourage critical thinking about better strategies for minimizing total energy use. Innovative new developments in materials science and engineering are essential to solving these problems and ensuring a better future.

\section{Megan Frary \\ Associate Professor, \\ Boise State University}

Member, Women in Science Committee

I was happy to see the National Sci-

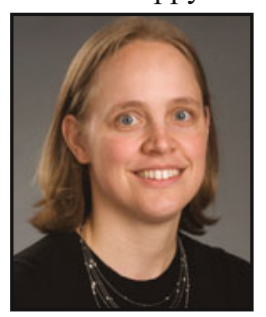
ence Foundation launch its familyfriendly initiative this year. While it is still hard to balance starting a family and a research program, these policies will be especially helpful to early-career faculty and may help retain bright researchers, not only in materials science and engineering, but across all disciplines. I hope to see, in 2012 and beyond, other agencies formalize similar policies that make

\section{David Furrer \\ Senior Fellow Discipline Lead, Pratt \& Whitney \\ Member, ICME Committee \\ 2011 brought the announcement of the Materials Genome Initiative by U.S. President

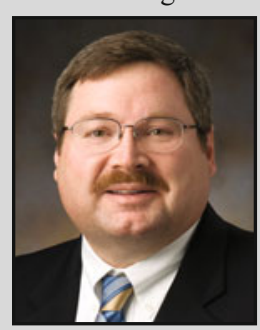 Barack Obama. This is a significant milestone in the development of integrated computational materials engineering (ICME) and re- lated materials technologies. This newly announced initiative has energized the materials community to work together to identify and overcome the gaps that prevent the widespread deployment of computational materials methods within academia, industry, and government. As part of these efforts, materials societies are joining forces to initiate the development of infrastructural tools to enable ICME implementation growth and sustainment.}

The result of this national initiative will likely be the establishment of focused efforts by universities, professional societies, and consortia in the area of computational materials science and engineering. These efforts will accelerate the development of core materials computational capabilities, including models and simulation software. Other needed technologies will undoubtedly be propelled to the forefront of research efforts, including methods for verification and validation of models, quantification of prediction uncertainty, data management systems, data with well-established pedigree information, standards for linkage of models, methods for enhanced communication of data, and enhanced component and materials definitions. Additionally, materials development and optimization will become more closely linked to component and manufacturing process design and development. 
the materials research community one that allows all of its members to thrive, both personally and professionally.

\section{Micah J. Hackett \\ Nuclear Materials Scientist, \\ TerraPower, LLC \\ Member, TMS Nuclear Materials Committee}

The most significant development

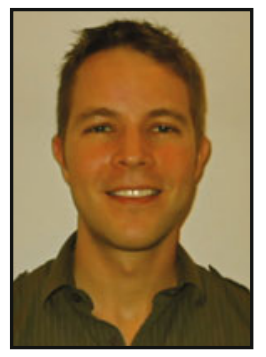
this year, in my opinion, is the commercial introduction of the allelectric vehicles (Chevy Volt, Nissan Leaf) targeted to mainstream consumers. These vehicles have required significant investments over many years in the development of high-density batteries, and in time, all-electric vehicles will revolutionize the auto industry. Though the transformation from gasoline engines to all-electric vehicles may occur slowly, the consequences will be far reaching. The question of where all of the additional electricity to power our vehicles will come from may even spur another revolution (hopefully) in how we electrify our country and planet.

\section{Sandip Harimkar}

Assistant Professor,

Oklahoma State University

Chair, Surface Engineering Committee

This year, we saw significant re-

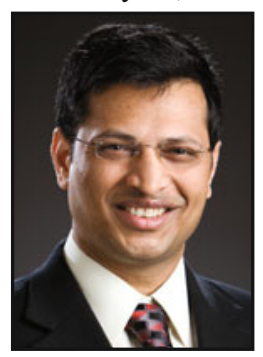
search efforts in the development of thick amorphous and nanostructured composite coatings. Various surface engineering approaches based on laser processing, thermal spraying, electroplating, solid-state sintering, and severe surface deformation have been reported for the processing of these coatings. While the control of phase structure (amorphous or crystalline) and grain-size/nano-fillers distribution still seems challenging, these processes are likely to become increasingly important for large-area processing of components. These amor- phous and nanostructured coatings can potentially be used for a wide range of applications, including hard chromium replacement, bio-implant coatings, low-friction coatings, and hard and corrosion-resistant coatings.

\section{Edward D. Herderick}

Applications Engineer, EWI

Member, Public and Governmental

Affairs Committee

Nuclear power is the largest carbon-

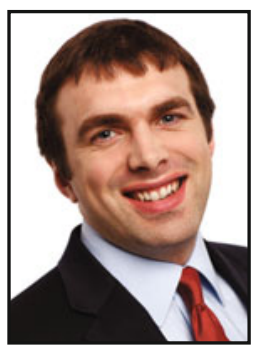

free energy source in the world and will continue to be a key pillar in the effort to reduce global climate change emissions. Therefore, it is imperative to continue technology innovation at existing reactors. The disaster at Fukushima Daiichi following the Japanese earthquake and tsunami poses a key challenge to the materials community: Are there materials innovations that can fundamentally improve safety at existing light water reactors? Fortunately, the answer is yes, though there is much work to be done by the materials community. Transitioning to a silicon carbide based fuel cladding from the existing zirconium cladding would lead to orders of magnitude in safety improvement. This is a materials challenge at its core and would be the biggest paradigm shift in light water reactor materials development since their original design and introduction.

\section{Norbert Hort}

Head, Magnesium Processing

Department, MagIC - Magnesium

Innovation Centre, Germany

Vice Chair, Magnesium Committee

Magnesium alloys as implant ma-

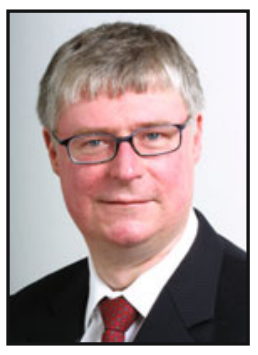
terials are a most interesting development. Magnes i u m-bas ed implants can be used in the musculoskeletal or the cardiovascular system. In the latter, magnesium coronary stents already have been used in clinical tests. Their advantage lies in the fact that they can be used as normal stents, but will disappear after some time. The area where the stent is applied is still a distorted area and it is most likely that it will be blocked by plaque again. When using a permanent stent, it is almost unlikely that another stent can be placed at this position. A bypass would be necessary. The magnesium stent instead dissolves, and when the blood vessel is blocked again, a new stent could be placed at the same place.

In a number of other cases, an implant needs to be removed. Steel or titanium implants have a Young's modulus that is far larger than that of a cortical bone, for example, and their strength is at least one order of magnitude larger than that of bone. Stress shielding can be quite often observed and a second surgery is frequently necessary. Imagine how it would be if this second surgery could be avoided due to an implant that dissolves and disappears after it fulfilled its function? It might be that this dream can be made true if the implant would consist of a magnesium alloy.

\section{Koenraad G.F. Janssens}

Staff Scientist, Laboratory for

Nuclear Materials,

Paul Scherrer Institute, Switzerland

Member, Nuclear Materials Committee

The ramifications of the Fukushima Daiichi catastrophe in Japan could be quite large in the country where I live, since Switzerland will probably discontinue the building of new nuclear plants in the near future. In and outside of Switzerland, I believe there will be more of a push - and larger budgets for materials research related to alternative energy resources. How far that will change the energy landscape we live in, only the future can tell.

\section{Jian Luo \\ Associate Professor, \\ Clemson University \\ Vice Chair, Thin Films \\ and Interfaces Committee}

In February 2011, Samuel S. Mao and co-workers at the Lawrence Berkeley National Laboratory and University of California at Berkeley reported an "unconventional" route to utilizing spontaneously formed 


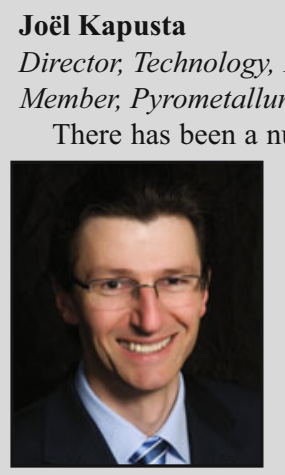

Joël Kapusta

Director, Technology, Mining \& Metals, BBA Inc., Montréal, Québec, Canada Member, Pyrometallurgy Committee

There has been a number of important developments in pyrometallurgy around the world this year, though the most significant, in my opinion, has occurred very close to my home in Canada, in the town of Sudbury, Ontario, one of the major districts of the Canadian nonferrous metals extraction and processing industry.

That major development is the advancement in the previously announced commitment by Vale to address atmospheric emissions, both gaseous and particulates, at its largest and oldest nickel smelting operations, the Copper Cliff smelter. The project undertaken by Vale is significant in both its proposed environmental impact (e.g., a further reduction by $70 \%$ of its current $\mathrm{SO}_{2}$ emissions) and its allocated overall budget, reported to be around $\$ 2$ billion.

After having been accustomed, over the last two decades, to multi-billion dollar project announcements to develop and build hydrometallurgical plants to process nonferrous metals, this project from Vale particularly stands out since no effort over a billion has been carried out in pyrometallurgy in the western world for a long time. Vale's also stands out as an essentially environmental project. As Angie Robson, manager, corporate affairs, Ontario Operations with Vale, was reported saying in a recent article, "We don't get any more nickel as a result, there's no operational benefit. But it will allow for the sustainability of our operations for decades to come."

A possible ramification of these major emissions reduction projects could be a change in the perception that metal extraction via pyrometallurgical processing, viewed as inherently polluting, can actually meet new environmental regulations legislated by local governments, and more significantly, that even older smelters can be economically brought to those new standards and regulations.

My hope, however, is that such projects will come to the attention of students in the fields of minerals, metals, and materials, and that many of them will be attracted by the human and technical challenges to continue transforming older smelters into modern metallurgical complexes that operate in the respect of more and more stringent environmental standards, while still generating wealth for the regions they are located in, the employees, and the employers.

Striving to attract and mentor a new generation of engineers, and help them develop their skills and employ their environmental motivation toward technical solutions to address air, land, and water pollution is part of that long-term dream. This new generation of engineers will also be challenged to modify existing processes by further improving process efficiency and reducing energy requirements, so as to demonstrate that sustainability can be an avenue for continued profitability.

disordered surface films to drastically

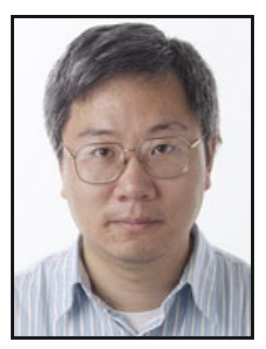

enhance the efficiency of the photocatalytic water splitting of $\mathrm{TiO}_{2}$ anatase nanoparticles [Chen, Liu, $\mathrm{Yu}$, and Mao, $S c i-$ ence 331: 746-49 (2011)]. Specifically, they annealed anatase nanoparticles at $200^{\circ} \mathrm{C}$ in 20 -bar $\mathrm{H}_{2}$ to allow the spontaneous formation of 1-2 nm thick, glass-like, surface films. Consequently, the normally white anatase powder was transformed to a "black $\mathrm{TiO}_{2}$ " powder, which led to drastically enhanced efficiency for photocatalytic water splitting under the irradiation of solar light. They also conducted first- principle calculations to illustrate that the lattice disorder in the nanoscale surface films is responsible for creating the mid-gap states that significantly increase the solar adsorption.

The Berkeley work on $\mathrm{TiO}_{2}$ is particularly inspiring and interesting because it has exemplified a potentially transformative approach of utilizing an "interfacial phase" to achieve a superior property that is not attainable by conventional bulk phases or nanoparticles. Further studies have to be conducted to verify that the Berkeley study can be scaled up for the production of commercial photocatalysts, as well as to understand the underlying thermodynamic mechanism for forming this unique class of nanoscale glass-like surface films. It will be ex- citing to seek other examples of utilizing "interfacial phases" to achieve superior properties unattainable by conventional bulk phases, beyond photocatalysts.

\section{Navin Manjooran}

Global Manager (SAM), Energy,

Siemens AG, Germany

Member, Nanomaterials Committee

In my opinion, the developments in

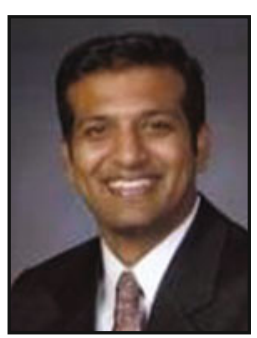

high-temperature-

tolerant material systems (ceramics, coatings) are game-changing advancements. These technology leaps help achieve higher engine operating temperatures, resulting in higher efficiencies in the power generation energy business. The technological advancements in these high-temperature material systems will continue to drive combustion turbines operated at higher and higher efficiencies.

\section{Toni Marechaux}

Senior Scientist, Strategic

Analysis, Inc.

Member, ICME Committee

There's been tremendous progress

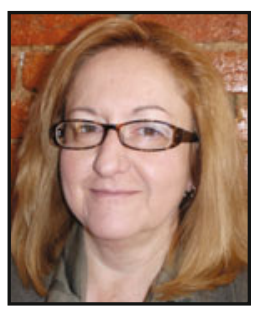
in 2011, which makes choosing what is most significant very difficult! My selection, however, is the recognition of advances in digital direct manufacturing (DDM). Entrepreneurs all over the world are beginning to understand that they can design and manufacture just about anything locally and on-demand. This is going to drive the need for materials data application programming interfaces (APIs), incorporating engineering properties and metadata. The Materials Genome Initiative is a great start on this.

A year from now, DDM is going to change the world of ICME in many ways. I feel things are going to move very fast on this, and while the government is spearheading materials data initiatives today, industry will be the driver in the very near future. 
Chamini L. Mendis

National Institute for Materials

Science, Japan

JOM Advisor, Magnesium Committee

The adoption of magnesium alloys in

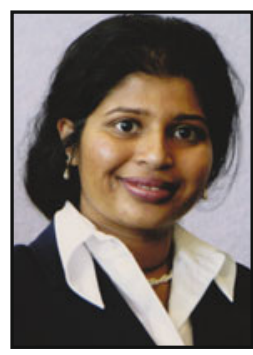
aeronautical applications in civil aviation by the Federal Aviation Administration is a significant development. This was introduced during the TMS 2011 Annual Meeting \& Exhibition and can expand the scope of magnesium alloy development for structural applications by expanding the types of applications. Aviation applications do not require as stringent a requirement to reduce costs as automotive settings. This makes the introduction into commercialization of new high-strength, but higher-cost, structural magnesium alloys easier. This can enhance the application of magnesium alloys in other structural applications, such as automotive vehicles and personal electronics.

Norbert L. Piret

Principal, Piret \& Stolberg Partners, Germany

Member, Recycling and Environmental Technologies Committee

A critical development was the de-

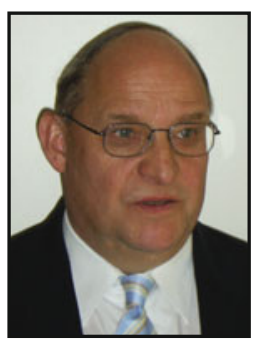
cision in 2011 of a major United States zinc producer to implement, on a large commercial scale, a hydrometallurgical zinc smelting plant, involving the novel zinc solvent extraction process. This enables high-grade zinc metal to be produced directly from secondary zinc - mainly crude zinc oxideobtained in the recycling of steel mill dust. This new process, substituting the existing pyrometallurgical process, contrasts the latter by a low environmental impact, particularly a very low carbon footprint.

The successful implementation of the process on this major scale sets a benchmark to zinc producers and is expected to enhance steel mill dust recy- cling, now standing at a rate of $50 \%$ on a worldwide basis.

\section{W. Jud Ready}

Principal Research Engineer and Adjunct Professor, Georgia Tech

Research Institute

Member, Public and Governmental Affairs Committee

The most significant issue related to

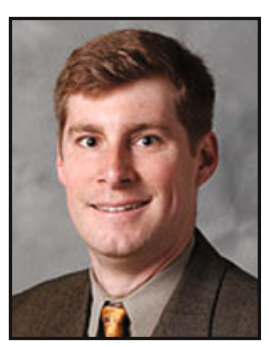
materials this past year has been the recognition-at the highest levels of governmentthat materials developments are key to virtually everything in society. This recognition has come in the form of the White House Materials Genome Initiative, that is aimed at reducing by $50 \%$ the time- and cost-to-market for new advanced materials.

My primary concern is that, given the intensely partisan state of affairs in Washington, this worthy initiative will instead be viewed in an "us vs. them" manner following elections, and may simply get wiped away in the all-toofrequent partisan "cleansing" of programs that are created by the opposing party. Though I believe many initiatives in Washington are partisan in nature, this is not one of those and it should have support from both sides of the aisle, as well as society in general. I personally plan to work to educate policy people on the non-partisan importance of this specific initiative, which will hopefully be sustained across multiple administrations and parties - and I encourage other TMS members to do the same!

\section{Raul B. Rebak}

Corrosion Engineer,

GE Global Research

Chair, Nuclear Materials Committee

As the chair of the TMS Nuclear

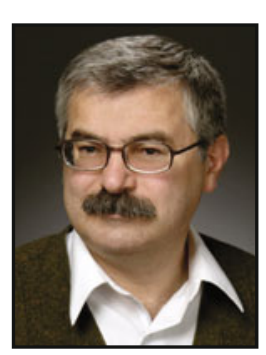

Materials committee, the most significant news in nuclear materials and corrosion for 2011 was the Fukushima disaster in Northeast Japan. The mass media discussed details on how zirconium was reacting with water to form hydrogen gas, as well as how the gas was leaking out of the container (and igniting). The news also stressed why water was so important in a nuclear reactor and that the lack of cooling (no pumps) accelerated the degradation of the materials inside the reactor. The coverage in the mass media of this disaster was in general negative and created fear. But, at least materials were discussed.

The potential ramification of this materials/corrosion issue is a complete re-evaluation of the safety measures at commercial nuclear power plants worldwide, and another long delay in the recovery of the production of nuclear energy, mainly in the western world.

\section{Mark Schlesinger}

Professor of Metallurgical

Engineering, Missouri University

of Science and Technology

Past Chair, Recycling and

Environmental Technologies

\section{Committee}

The continuing high price of many

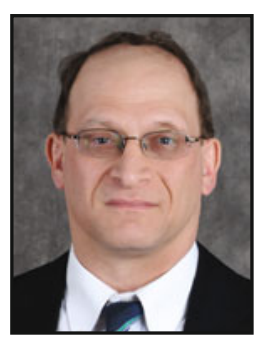
metals in 2011 had a significant impact on their use by society. On one hand, high prices encouraged recycling, especially of precious metals. On the other hand, they also encouraged metal theft, especially of copper wiring. The flowcontrol restrictions and other responses taken by government in response to this have a significant potential effect on the recycling industry in 2012.

\section{Junji Shibata}

Professor, Chemical Engineering,

Kansai University, Japan

Member, Recycling and Environmental Technologies Committee

Rare earths and rare metals have be-

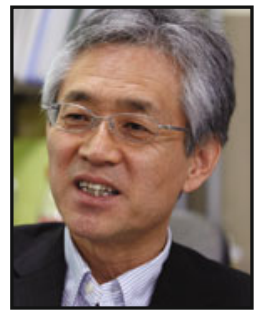
come important issues in the last two years. Japan and the United States had a rare earth workshop last year at the Lawrence Livermore Nation- 
al Laboratory. There was also a Trilateral European Union-Japan-U.S. Workshop on Critical Materials research and development in Washington D.C. at the U.S. Department of Energy this October. There were arguments to recover rare earths and rare metals from wasted materials and to use commutative complex materials without rare earths and rare metals. Recycling is important, but recycling should be done by a zero emission process, not an environmentally friendly process.

\section{Katsuyo Thornton \\ Associate Professor, \\ University of Michigan \\ Chair, ICME Committee}

President Obama's support, ex-

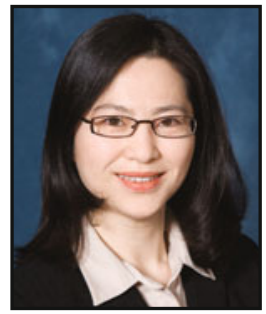
pressed through the Materials Genome Initiative (MGI) for Global Competitiveness, has been a huge boost to ICME. This is an initiative that was announced in June that aims to "double the speed with which we discover, develop, and manufacture new materials." ICME is a major component of such an effort, and it has brought a spotlight on ICME, which will bring resources needed in moving forward.

A second major development for ICME was the First World Congress on ICME, which took place in July. It provided a forum for researchers across academia, industry, and national laboratories, as well as government representatives, to exchange information and develop the direction of ICME. It was an overwhelming success with more than 240 attendees.

With the solidly established ICME community base and governmental backing through the MGI, we expect to see many new ICME developments as well as the growth of existing ones in the coming years. I think we are looking at an exciting few years ahead!

\section{Vasisht Venkatesh}

Lead Materials Modeling Engineer, Pratt \& Whitney

Chair, Titanium Committee

New developments in the area of ad- vanced characterization techniques that

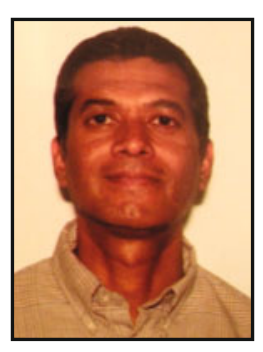
can quickly identify and quantify morphologies and crystal orientations of key phases in alpha+beta titanium alloys are very exciting. These techniques, in turn, are helping researchers assemble databases that contain representative microstructural feature elements that will be used to build microstructure-property relationships. The development of fast-acting physics-based models that will be able to query the microstructure databases for the prediction of final mechanical properties based on strain path/process dependent microstructure evolution would enable improved component designs.

\section{Edgar E. Vidal}

Manager, Market \& Business

Development, Brush Beryllium

\& Composites, Materion Corporation

Member, Hydrometallurgy and

Electrometallurgy Committee

The fact that metal commodities have

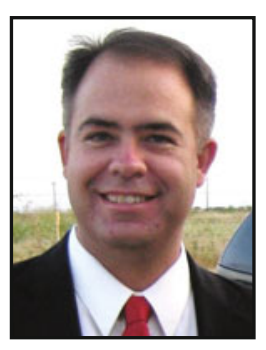

spiked this year has been great news for the mining and extractive industries. Moreover, because of the metal prices, and in particular those of precious metals, recycling electronic waste is becoming more and more interesting as a secondary source.

The August 2011 JOM issue summarizes a series of articles of work being performed in recycling valuables from electronic waste in which hydrometallurgy and electrometallurgy are critical. Large metal companies are starting to invest in research focused on increasing the yields and recovery from electronic waste, and so is the United States government through institutions like the National Science Foundation. It would not surprise me if more legislation is passed so valuable metals and alloys contained in electronic waste are not landfilled and a mandatory pretreatment is performed.

\section{Julia R. Weertman}

Walter P. Murphy Professor Emerita, Northwestern University

Member, Women in Science Committee

The advances in research are so var-

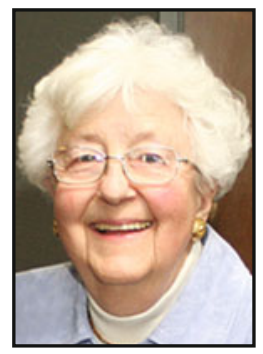
ied and remarkable that it is hard to choose one. In materials science and engineering (MSE) education, the field keeps expanding from the original concepts of the unity of principles behind metals, ceramics, and polymers - It's been broadened to include biomaterials and biological materials, and now encompasses computational MSE. Quite a curriculum for students to master! Of course this is not a development limited to 2011. It has been going on for some time. But, it is what I think of as the current state of MSE education.

\section{Zhenguo (Gary) Yang}

Laboratory Fellow, Pacific

Northwest National Laboratory

Member, Energy Conversion

and Storage Committee

The most significant development in

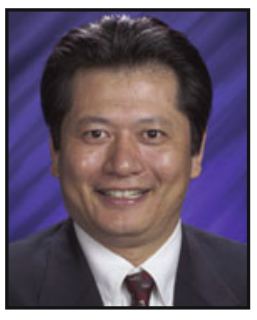
this past year is the growth in interest in electrical energy storage for renewable integration and grid applications. This has been spurred by the increasing use of intermittent renewable powers and concerns over the resource constraints of fossil fuels, as well as their environmental consequences. TMS has been part of this emerging area, with efforts in helping the United States government to develop roadmaps and establishing a committee to promote the field in the materials community.

The single event that has further amplified the need of stationary storage is the Fukushima nuclear disaster. This changed perception of nuclear power and compelled Germany to shut down its $17 \mathrm{nu}$ clear power plants by 2022. Those plants provide about $20 \%$ of the country's power use. The clean alternatives are renewable sources and their significant penetration relies on deployment of effective electrical storage. 